\title{
Disulfonated Xantphos for Mass Spectrometric Mechanistic Analysis
}

\author{
Mathias Paul, Katarina Laketic and J. Scott Mclndoe* \\ Department of Chemistry, University of Victoria, PO Box 1700 STN CSC, Victoria, BC V8W \\ 2Y2, Canada. Fax: +1 (250) 721-7147; Tel: +1 (250) 721-7181; E-mail: mcindoe@uvic.ca
}

\begin{abstract}
Xantphos is a wide bite angle bisphosphine ligand that finds wide application in catalysis. Tracking its behavior during reactions under realistic reaction conditions can be difficult at low concentrations, and while electrospray ionization mass spectrometry (ESI-MS) is effective at realtime monitoring of catalytic reactions, it can only observe ions. Accordingly, we experimented with the dianionic disulfonated version of xantphos as a charged tag for mechanistic analysis. It proved to behave exactly as hoped, providing good intensity and enabled the direct study of both an initial binding event (to copper, very fast) and a subsequent transfer to another metal (palladium). Its dianionic nature makes it especially promising for the study of reactions in which metals change charge state, because a cationic metal complex with an anionic ligand is an invisible zwitterion, whereas a dianionic ligand would instead make the same cationic complex appear due to the overall charge of -1 . As such, disulfonated xantphos holds genuine promise as a mechanistic probe in real time analysis using mass spectrometry.
\end{abstract}

\section{Keywords}

Charge-tagged ligands, mass spectrometry, electrospray ionization, kinetics

\section{Graphical abstract}

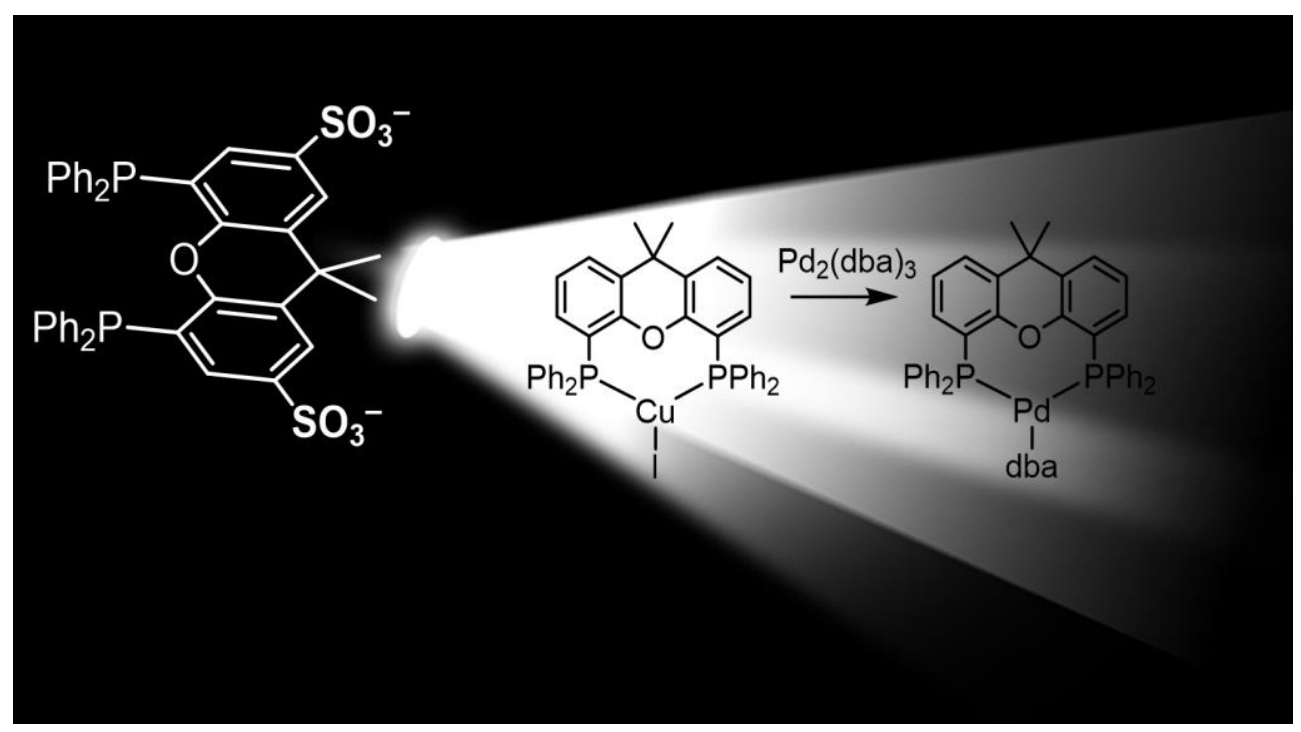




\section{Introduction}

Catalytic systems are tough to study directly. Even in homogeneous systems, the solution is a complex mixture of solvent, reactants, products, and byproducts. ${ }^{1-5}$ Catalytically relevant species are typically much less abundant than the aforementioned and partitioned between precatalyst, resting state(s), decomposition products, and

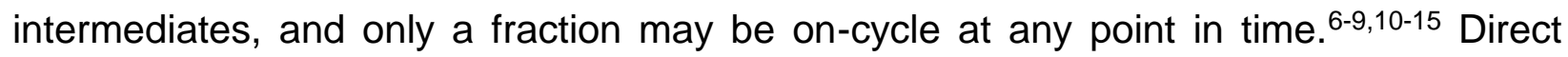
methods of investigation need to be sufficiently sensitive to delve down to very low concentration levels, and in electrospray ionization mass spectrometry (ESI-MS), chemists have a tool to do exactly that. However, the technique has an Achilles heel: it operates solely on ions, transferring them to the gas phase for analysis, and ignoring neutral compounds, which are unaffected by the electric fields used to manipulate charged species. Chemists wishing to probe catalytic reactions by ESI-MS need to either limit themselves to ionic catalysts or come up with ways to tag otherwise neutral compounds with a charge to render them visible. ${ }^{16-24}$ Here, we have adopted the disulfonated version of the popular wide bite angle ligand xantphos, ${ }^{25-28}$ and examined its potential as a charged-tagged ligand for mechanistic analysis. ${ }^{29}$

We chose to examine the coordination of disulfonated xantphos to copper(I) iodide, as this ligand/metal combination has been used with success in various catalytic transformations but the ligand is also wide-spread in other transformations. ${ }^{25,} 30-35 \mathrm{We}$ were particularly interested in the report ${ }^{77 a]}$ that a co-catalytic system for direct arylation of heteroarenes involved a xantphos complex of copper that did not exchange ligands with the palladium present (Scheme 1 and 2). Given that xantphos typically enthusiastically binds $\mathrm{Pd},{ }^{36-38}$ we planned to probe the copper/palladium/xantphos interaction in more detail using real-time ESI-MS, ${ }^{39,40}$ as a way to assess its efficacy as a reaction probe and to point the way to further mechanistic studies. 


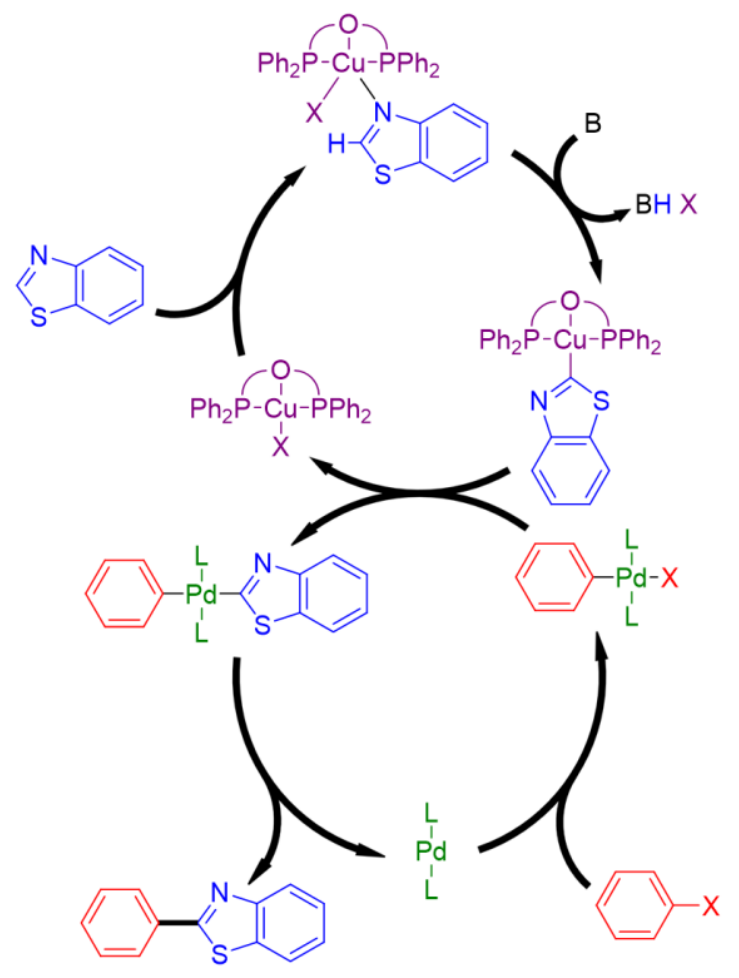

Scheme 1. Mechanistic interpretation as proposed by Huang and coworkers. ${ }^{34,41}$

As can be seen in Scheme 1, Huang and coworkers interpret the catalytic direct arylation of heteroarenes as follows. The preformed copper-xantphos complex I coordinates the bezothiazole first to from the $\mathrm{N}$-coordinated species II and deprotonation yields carbene complex III. At the same time, a palladium(0) catalyst IV undergoes oxidative addition with a phenyl halide to form the palladium(II) intermediate $\mathbf{V}$. Through transmetallation, the benzothiazole is transferred to the palladium center, regenerating the copper cocatalyst I and generating the palladium(II) species VI. In the final step of these $\mathrm{Pd} / \mathrm{Cu}$ double-cocatalytic cycles, the arylated product is formed through reductive elimination, regenerating the active palladium(0) catalyst. At no point in their study was $\mathrm{Pd} / \mathrm{Cu}$ crossover reaction on the xantphos ligand observed. ${ }^{34}$

\section{Results and Discussion}

Disulfonated xantphos was synthesized following a procedure derived from the one used by van Leeuwen and coworkers (Equation 1). ${ }^{27}$ To make the ligand more soluble in organic solvents, we replaced the sodium counterions with bulky bis(triphenylphosphine)iminium cations. 


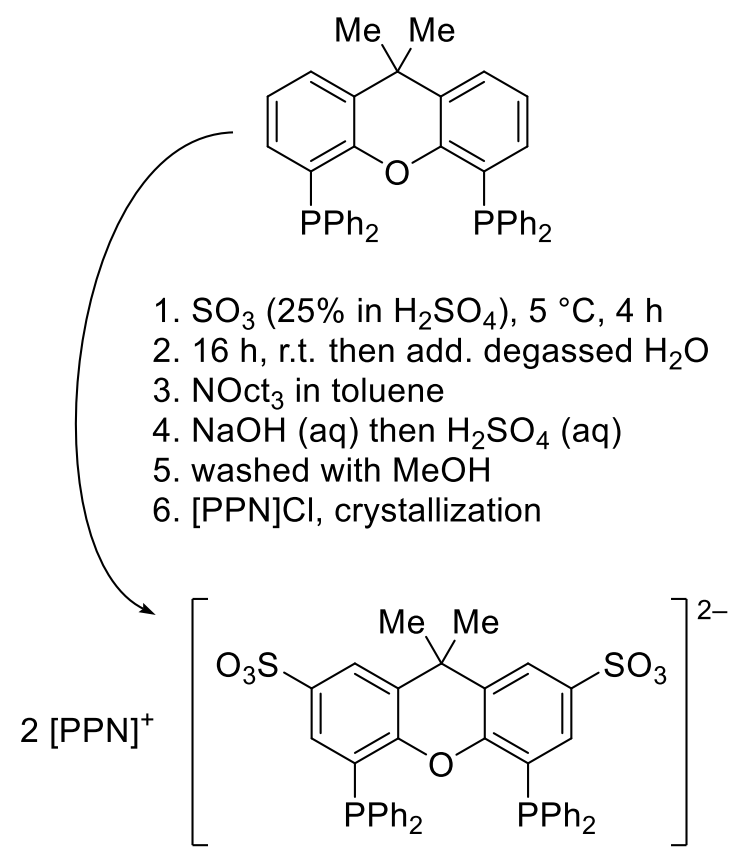

Equation 1: Synthesis of the sodium salt of sulfonated xantphos by a procedure derived from the one used by van Leeuwen and coworkers, ${ }^{27}$ followed by ion exchange.

We characterized the crude sodiated sulfonated xantphos dianion, henceforth [1] ${ }^{2-}$, mass spectrometrically using the negative ion mode. It provided a strong signal at $\mathrm{m} / \mathrm{z} 368$, with an isotope pattern commensurate with a dianionic formulation (peaks in the pattern $\mathrm{m} / \mathrm{z}$ 0.5 apart, see Figure 1). The spectrum looks more complicated than expected for a clean compound, but combinations of the dianion and the sodium cation and trace oxidation readily account for nearly all species. ${ }^{42}$ The exception is a small amount of triply sulfonated xantphos at $m / z 272$. 


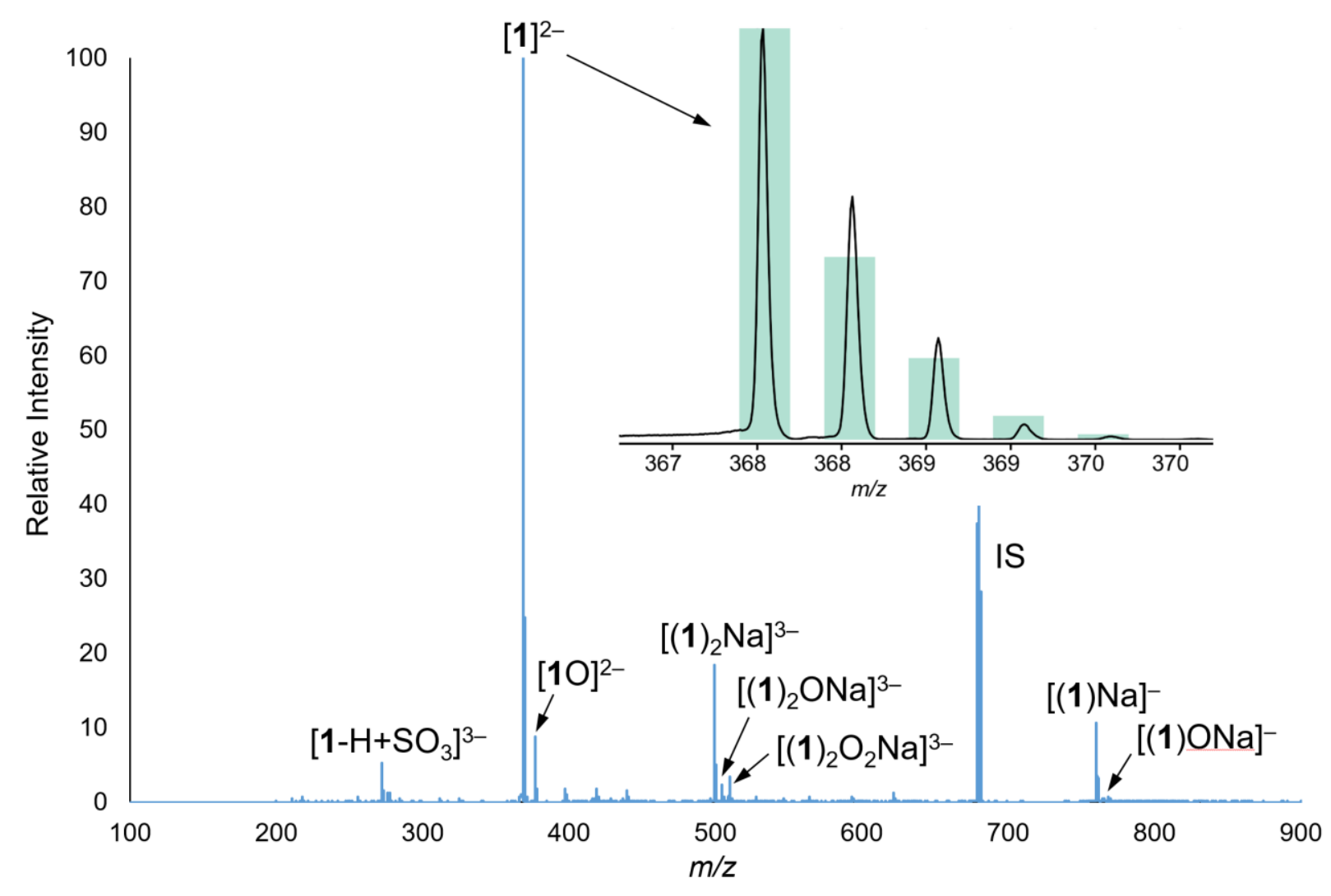

Figure 1. Negative ion mass spectrum of crude [1 $]^{2-}$ in acetonitrile. Inset (a): isotope pattern. IS $=$ internal standard $=\left[\mathrm{B}\left(\mathrm{C}_{6} \mathrm{~F}_{5}\right)_{4}\right]^{-}$.

In order to examine the reactivity of ions using ESI-MS, we employ pressurized sample infusion (PSI) to monitor the reactions continuously in real-time. ${ }^{43} \mathrm{PSI}$ is essentially a cannula transfer using a capillary, which generates flow rates suitable for ESI-MS analysis. ${ }^{44}$ When we examined the reaction between $\mathrm{Cul}$ and $\mathrm{PPN}_{2}[1]$ in acetonitrile at room temperature (Figure 4), we were surprised to see, that ligand association happened faster than the timescale of the PSI-ESI-MS experiment (which requires $10 \mathrm{~s}$ for the solution to be pumped from the reaction flask to the mass spectrometer). ${ }^{45}$ 


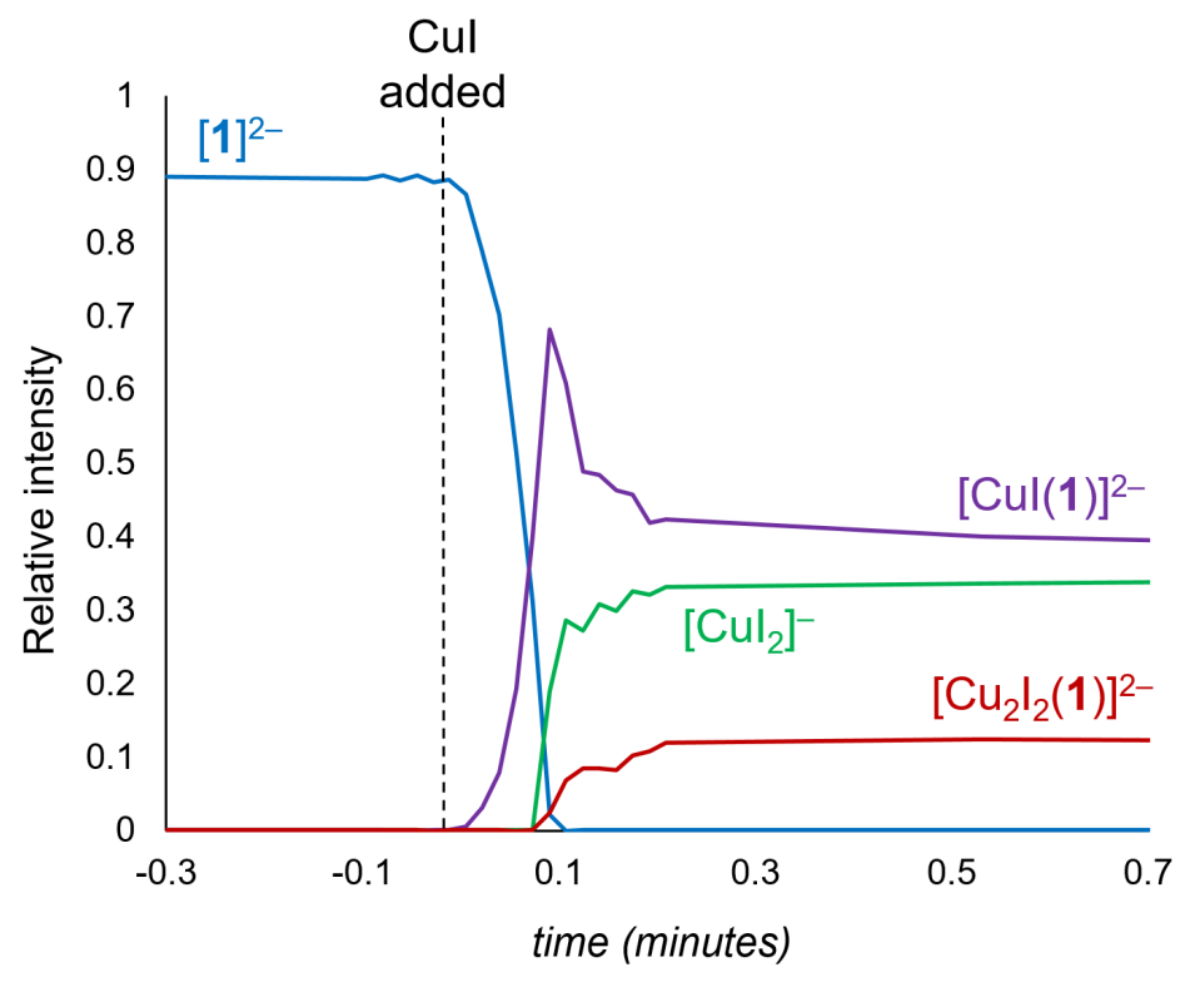

Figure 2. Reaction profile for the combination of $[\mathrm{PPN}]_{2}[1]$ and $\mathrm{Cul}$ in acetonitrile. Intensities are normalized to the total ion current of the species shown.

As the main product, a dianionic complex whose mass spectrometric profile corresponded to $[\mathrm{Cu}(\mathbf{1})]^{2-}$ in terms of $\mathrm{m} / \mathrm{z}$, isotope pattern and MS/MS behavior (Figure 3 ). It is reasonable to assume rapid association reaction happens because of the chelate effect of the bidentate $[1]^{2-}$ which can therefore abstract copper from the tetrakis(acetonitrile)copper(I) complex. 


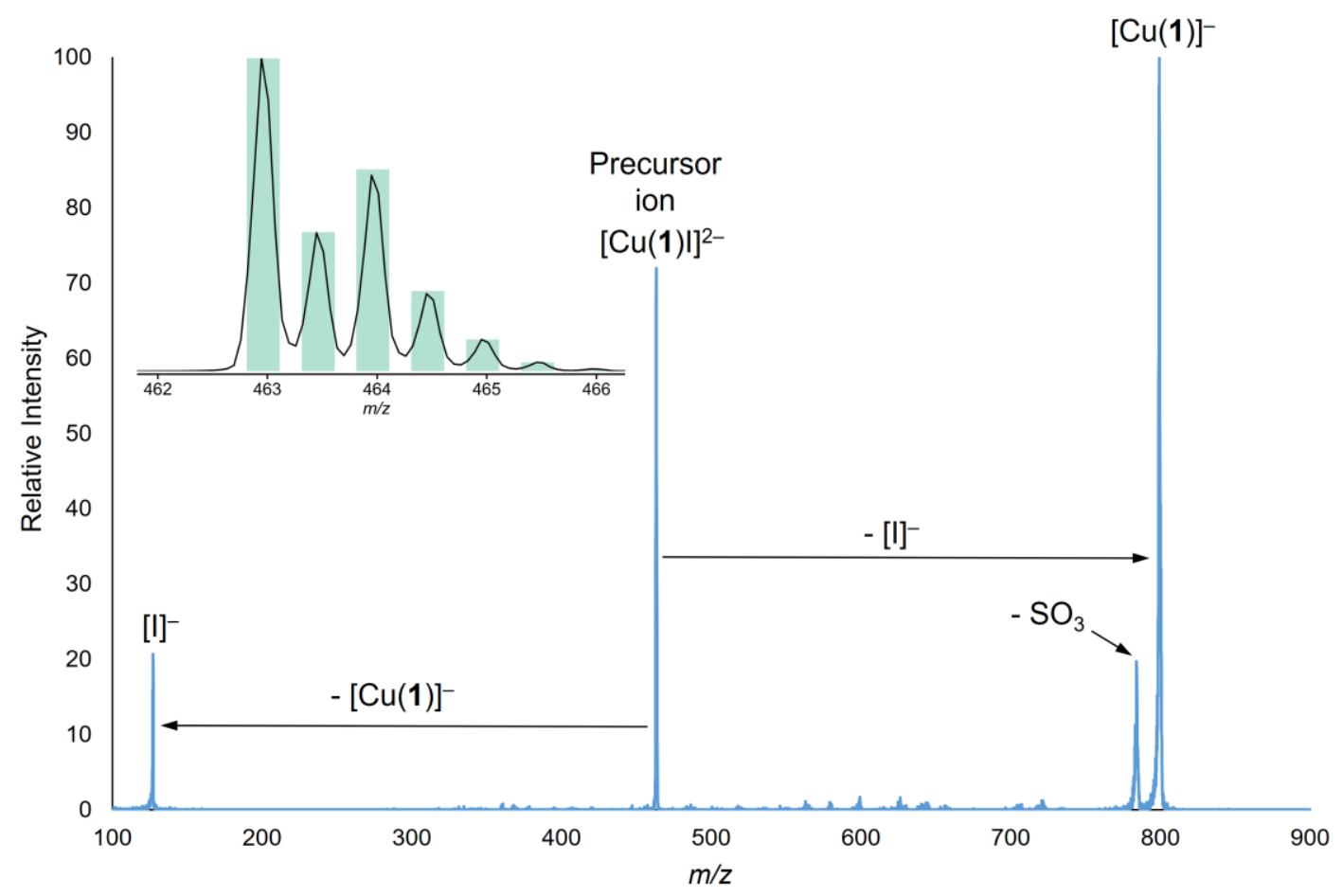

Figure 3. Negative ion product ion mass spectrum of $[\mathrm{Cu}(\mathbf{1})]^{2-}$. Inset: isotope pattern (line) shown with simulated pattern (bars).

As seen in Figure 3, [Cu(1)I] $]^{2-}$ at $m / z 463$ undergoes unimolecular decomposition in the gas-phase primarily by loss of $\mathrm{I}^{-}(\mathrm{m} / z 127)$ to generate $[\mathrm{Cu}(\mathbf{1})]^{-}, \mathrm{m} / z \mathbf{7 9 9}$. A small amount of oxygen atom loss from this ion is also observed $(\mathrm{m} / \mathrm{z} 783)$.

The straightforward production of $[\mathrm{Cu}(\mathbf{1}) I]^{2-}$ in solution provided an opportunity to assess the relative propensity of binding of the disulfonated xantphos [1] $\left.{ }^{2-}\right)$ for $\mathrm{Cu}(\mathrm{I}) \mathrm{vs}$. $\mathrm{Pd}(0)$. At $35^{\circ} \mathrm{C}$ this reaction is fast $\left(t_{1 / 2} \sim 1 \mathrm{~min}\right)$ and complete, with $1^{2-}$ abandoning $\mathrm{Cu}(\mathrm{I})$ entirely and taking up residence on $\mathrm{Pd}(0)$ (Figure 4). An equilibrium is established in which we observe both $[\mathrm{Pd}(\mathbf{1})(\mathrm{dba})]^{2-}\left(\mathrm{m} / \mathrm{z}\right.$ 538) and $\left[\mathrm{Pd}(\mathbf{1})(\mathrm{dba})_{2}\right]^{2-}(\mathrm{m} / \mathrm{z} 655)$ in an approximately $4: 1$ ratio. 


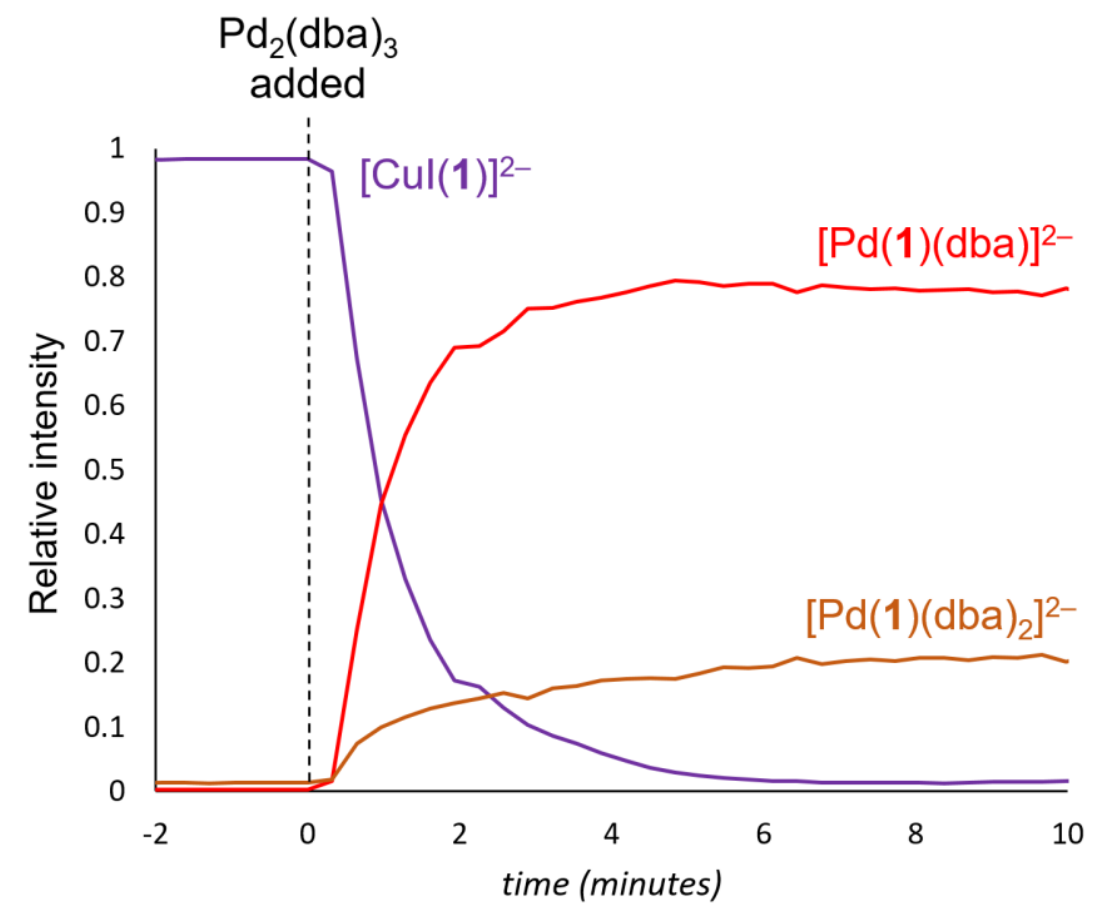

Figure 4. Reaction profile for the combination of $[\mathrm{Cu}(\mathbf{1})]^{2-}$ and $\mathrm{Pd}_{2}(\mathrm{dba})_{3}$ in acetonitrile. Intensities are normalized to the sum of all species containing $\mathbf{1}^{2-}$.

Both of these palladium(0) species readily lose dba in the gas phase when subjected to collision-induced dissociation (Figure 5). The coordination of the $\left[\mathrm{Pd}(\mathbf{1})(\mathrm{dba})_{2}\right]^{2-}$ is not provided by ESI-MS, but the presence of three bidentate ligands means a variety of possibilities depending on binding modes. 


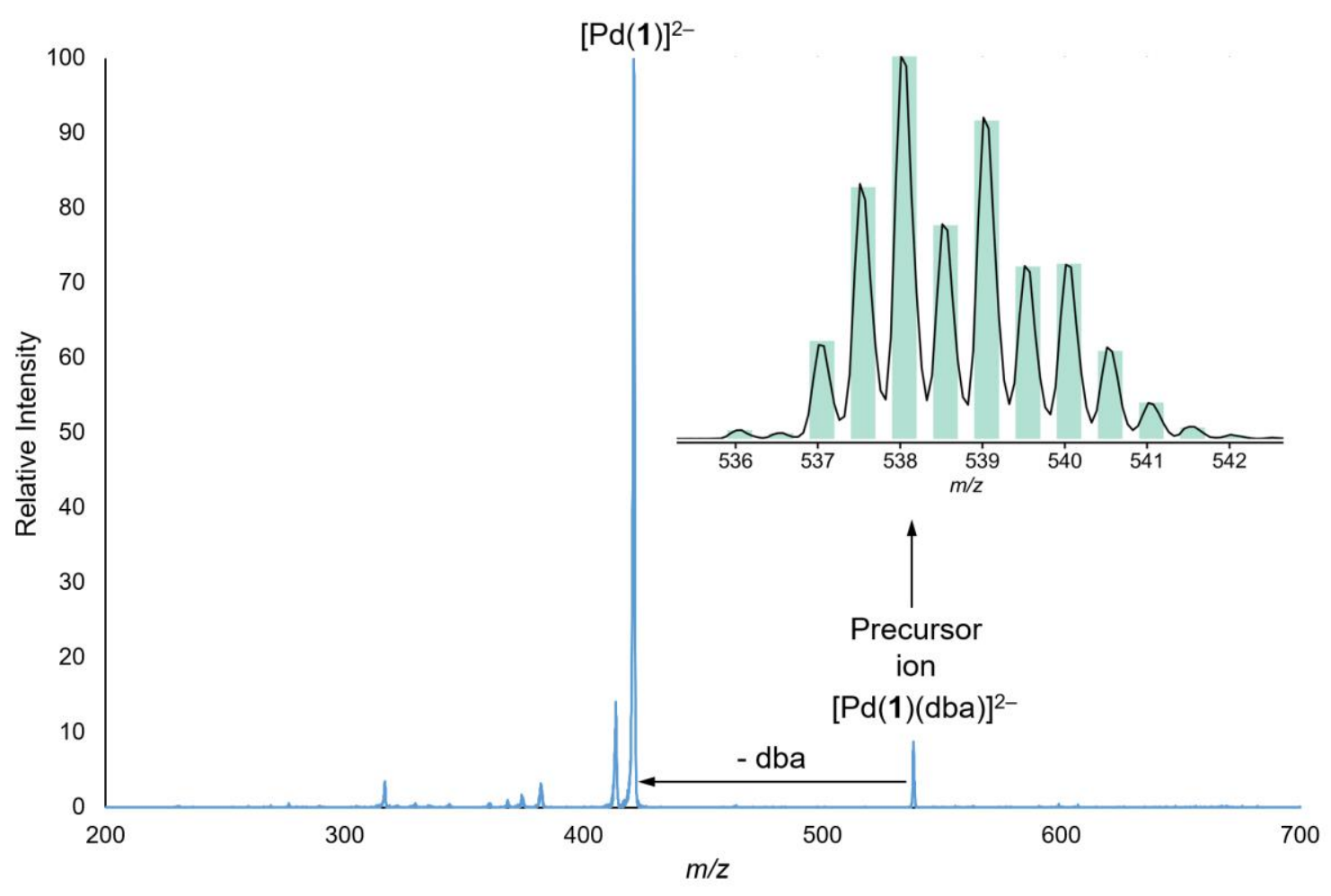

Figure 5. Negative ion product ion ESI mass spectrum of $[\mathrm{Pd}(\mathbf{1})(\mathrm{dba})]^{2-}$. Inset: isotope pattern shown with simulated pattern.

The published observation that xantphos does not transfer from $\mathrm{Cu}(\mathrm{I})$ to $\mathrm{Pd}(0)$ under catalytic conditions probably has several contributing factors. Toluene (the solvent used) is non-polar and minimally capable of mediating the ligand exchange, unlike the polar solvents used in this study. Acetonitrile is good at coordinating to both copper and palladium, and thus can stabilize the unsaturated intermediates required for xantphos to migrate from one metal to the other. Furthermore, the palladium in that case had a much more robust ligand set $\left(\mathrm{P}^{t} \mathrm{Bu}_{2} \mathrm{Cl}\right)$ rather than the weakly coordinating dibenzylideneacetone or acetonitrile ligand.

\section{Experimental}

All synthetic operations and catalyst preparations were carried out under a nitrogen $\left(\mathrm{N}_{2}\right)$ atmosphere, using Schlenk techniques and a glovebox.

Mass spectrometry was performed on a Waters Acquity Triple Quadrupole Detector (TQD). Chemicals were purchased from Sigma Aldrich. 


\section{Synthesis of 2,7-Bis(SO$\left.{ }_{3} \mathrm{Na}\right)$-Xantphos $\mathrm{Na}_{2}[1]$}

The method was adapted from van Leeuwen and coworkers. ${ }^{28}$ Under a stream of nitrogen, xantphos $(1.00 \mathrm{~g}, 1.73 \mathrm{mmol})$ was carefully added to oleum $\left(2.9 \mathrm{~mL}, 25 \% \mathrm{SO}_{3}\right)$ at $5{ }^{\circ} \mathrm{C}$ over the course of $4 \mathrm{~h}$. Upon addition, the resulting light brown solution was warmed to room temperature and stirred for $12 \mathrm{~h}$. After that, degassed water ( $15 \mathrm{~mL}$ ) was added slowly to the solution which resulted in a white suspension. Further degassed water $(20 \mathrm{~mL})$ was added at once, and the resulting yellow solution was then poured into a vigorously stirred solution of triisooctylamine (54 mmol, $2.3 \mathrm{~mL}$ in $10 \mathrm{~mL}$ of toluene). The toluene layer was washed twice with water before careful adjustment of the $\mathrm{pH}$ to 12 using $\mathrm{NaOH}$ solution $(6.25 \mathrm{M})$. The water layer was decanted and neutralized with $\mathrm{H}_{2} \mathrm{SO}_{4}$ $(3.00 \mathrm{M})$. Evaporation gave a white solid which was suspended in refluxing methanol and filtered hot. The filter cake was washed a couple of times with further hot methanol and the resulting filtrate evaporated to dryness. Further purification was done by refluxing the solid in $\mathrm{EtOH}$ which yielded a white solid. Yield: $1.10 \mathrm{~g}, 1.41 \mathrm{mmol}, 82 \%$.

\section{Synthesis of 2,7-Bis $\left(\mathrm{SO}_{3} \mathrm{PPN}\right)-\mathrm{Xantphos}[\mathrm{PPN}]_{2}[1]$}

A round bottom flask equipped with a stir bar was charged with the sodium salt of the sulfonated xantphos ( $\left.\mathrm{Na}_{2}[1]\right)$ ( $\left.0.507 \mathrm{~g}, 0.644 \mathrm{mmol}, 1.00 \mathrm{eq}\right)$ and $\mathrm{PPNCl}(0.739 \mathrm{~g}$ $1.288 \mathrm{mmol}, 2.00 \mathrm{eq}$ ). It was dissolved in as little methanol as possible (approximately $4 \mathrm{~mL}$ ). An equal amount of water was added, and the slightly cloudy mixture heated until it was clear again. This solution was placed in a fridge at $5^{\circ} \mathrm{C}$ for three days. The desired product precipitated as a colorless powder and was collected using vacuum filtration. It was washed using a cold methanol/water mixture (1:1) and dried under reduced pressure. Yield: $1.050 \mathrm{~g}, 0.579 \mathrm{mmol}, 90 \%$.

\section{Synthesis of Copper Complex [PPN $]_{2}[\mathrm{Cu}(\mathbf{1})$ I]}

A round bottom flask equipped with a stir bar was charged with [PPN]2[1] $(0.100 \mathrm{~g}$, $0.504 \mathrm{mmol}, 1.00 \mathrm{eq})$ and copper $(\mathrm{l})$ iodide $(0.096 \mathrm{mg}, 0.504 \mathrm{mmol}, 1.00 \mathrm{eq})$. To this acetonitrile $(10.0 \mathrm{~mL})$ was added and the flask sealed with a septum. The prepared flask was placed in an oil bath and stirred at $80^{\circ} \mathrm{C}$ for $15 \mathrm{~h}$. After the clear solution had cooled to room temperature, the volatiles were removed under reduced pressure to leave the product as a colorless powder. Yield: $0.594 \mathrm{~g}, 0.296 \mathrm{mmol}, 59 \%$.

\section{In Situ Synthesis of Palladium Complexes}

In a glovebox, [PPN $]_{2}[\mathrm{Cu}(\mathbf{1})$ l] $(10.8 \mathrm{mg}, 5.4 \mu \mathrm{mol})$ was placed in a Schlenk flask with dry acetonitrile $(10.0 \mathrm{~mL}) . \mathrm{Pd}_{2}\left(\mathrm{dba}_{3}(5.0 \mathrm{mg}, 5.5 \mu \mathrm{mol})\right.$ was placed in a round bottom flask with of dry $\mathrm{CH}_{3} \mathrm{CN}(5.5 \mathrm{~mL})$ and appeared as a black solution. The copper complex was initially monitored via mass spectrometry in negative ion mode under argon gas then the $\mathrm{Pd}_{2}(\mathrm{dba})_{3}$ solution was added at once to the copper complex solution and monitoring continued for any changes. 


\section{Conclusions}

The efficacy of disulfonated xantphos, PPN 2 [1], as a mechanistic probe in ESI-MS studies has been demonstrated in preliminary experiments. Dianionic ligands have a downside in that they have considerably different solubility profiles than their neutral analogues, but double upsides in the context of ESI-MS-based mechanistic analysis: they not only render neutral complexes visible, but they can also cope with changes in charge state during reactions. This property was evident indirectly in this study, because while both Cul and $\mathrm{Pd}(\mathrm{dba})$ are neutral fragments, we were also able to observe the monoanionic complex $[\mathrm{Cu} 1]^{-}$that initially formed when $[1]^{2-}$ reacted with $\mathrm{Cu}^{+}$. We anticipate this capability being useful in cases not just involving xantphos, but for any ligand that can be multiply charged through sulfonation (or other means), because instead of a cationic signal disappearing due to zwitterion formation, it will simply convert to a monoanion instead and remain trackable by ESI-MS. As such, [1] $]^{2-}$ promises to be a useful addition to the arsenal of mechanistic probes for the study of complex catalytic transformations.

\section{Acknowledgements}

JSM thanks the NSERC Discovery program for operational funding and CFI, BCKDF and the University of Victoria for infrastructural support. KL thanks the University of Victoria for a Jamie Cassels Undergraduate Research Award and NSERC for an Undergraduate Summer Research Award. Rina Concepcion and Dr Antonio Eduardo Miller Crotti are thanked for assistance with some experiments. 


\section{References}

1. Malig, T. C.; Yu, D. N.; Hein, J. E., A Revised Mechanism for the Kinugasa Reaction. J. Am. Chem. Soc. 2018, 140 (29), 9167-9173.

2. Isbrandt, E. S.; Sullivan, R. J.; Newman, S. G., High Throughput Strategies for the Discovery and Optimization of Catalytic Reactions. Angew. Chem. Int. Ed. 2019, 58 (22), 7180-7191.

3. Christensen, M.; Adedeji, F.; Grosser, S.; Zawatzky, K.; Ji, Y. N.; Liu, J. C.; Jurica, J. A.; Naber, J. R.; Hein, J. E., Development of an automated kinetic profiling system with online HPLC for reaction optimization. React Chem Eng 2019, 4 (9), 1555-1558.

4. van Leeuwen, P. W. N. M., Homogeneous Catalysis - Understanding the Art. 1 ed.; Kluwer Academic Publishers, Dordrecht, Boston, London: Netherlands, 2004.

5. Behr, A.; Neubert, P., Applied Homogeneous Catalysis. 1 ed.; Wiley VCH: Weinheim, Germany, 2012.

6. Selent, D.; Heller, D., Catalysis: From Principles to Applications. Wiley VCH: Weinheim, Germany, 2012.

7. Yarwood, J.; Douthwaite, R.; Duckett, S. B., Spectroscopic Properties of Inorganic and Organometallic Compounds. RSC Publishing: Cambridge, 2010.

8. Hartwig, J. F., Organotransition Metal Chemistry: From Bonding to Catalysis. University Science Books, VA: 2009.

9. Jordan, R. B., Reaction Mechanisms of Inorganic and Organometallic Systems. 3 ed.; Oxford University Press: New York, NY, USA, 2007.

10. Bligaard, T.; Bullock, R. M.; Campbell, C. T.; Chen, J. G. G.; Gates, B. C.; Gorte, R. J.; Jones, C. W.; Jones, W. D.; Kitchin, J. R.; Scott, S. L., Toward Benchmarking in Catalysis Science: Best Practices, Challenges, and Opportunities. ACS Catal. 2016, 6 (4), 2590-2602.

11. Xu, Q. S.; Guo, L. F.; Dinh, T. N.; Cheong, A.; Garland, M., Two-Dimensional (2D) Correlation Analysis and the Search for Intermediates: A Strictly Mathematical Approach to an Important Mechanistic Question. ACS Catal. 2015, 5 (6), 3588-3599.

12. Blackmond, D. G., Kinetic Profiling of Catalytic Organic Reactions as a Mechanistic Tool. J. Am. Chem. Soc. 2015, 137 (34), 10852-10866.

13. Grabow, K.; Bentrup, U., Homogeneous Catalytic Processes Monitored by Combined in Situ ATR-IR, UV-Vis, and Raman Spectroscopy. ACS Catal. 2014, 4 (7), 2153-2164.

14. Torres, A.; Perez, N. M.; Overend, G.; Hodge, N.; Heaton, B. T.; Iggo, J. A.; Satherley, J.; Whyman, R.; Eastham, G. R.; Gobby, D., High-Pressure In Situ NMR Methods for the Study of Reaction Kinetics in Homogeneous Catalysis. ACS Catal. 2012, 2 (11), 2281-2289.

15. Garland, M.; Li, C. Z.; Guo, L. F., Four Criteria for Evaluating Pure Component Spectral Estimates and the Subsequent Identification of Intermediates in Homogeneous Catalysis. ACS Catal. 2012, 2 (11), 2327-2334.

16. Iacobucci, C.; Reale, S.; De Angelis, F., Elusive Reaction Intermediates in Solution Explored by ESI-MS: Reverse Periscope for Mechanistic Investigations. Angew. Chem. Int. Ed. 2016, 55 (9), 2980-2993.

17. Iacobucci, C.; Reale, S.; Gal, J. F.; De Angelis, F., Dinuclear Copper Intermediates in Copper(I)-Catalyzed Azide-Alkyne Cycloaddition Directly Observed by Electrospray Ionization Mass Spectrometry. Angew. Chem. Int. Ed. 2015, 54 (10), 3065-3068.

18. Medeiros, G. A.; da Silva, W. A.; Bataglion, G. A.; Ferreira, D. A. C.; de Oliveira, H. C. B.; Eberlin, M. N.; Neto, B. A. D., Probing the mechanism of the Ugi four-component reaction with charge-tagged reagents by ESI-MS(/MS). Chem. Commun. 2014, 50 (3), 338-340.

19. Iacobucci, C.; Reale, S.; Gal, J. F.; De Angelis, F., Insight into the Mechanisms of the Multicomponent Ugi and Ugi-Smiles Reactions by ESI-MS(/MS). Eur. J. Org. Chem. 2014, 2014 (32), 7087-7090. 
20. Coelho, F.; Eberlin, M. N., The Bridge Connecting Gas-Phase and Solution Chemistries. Angew. Chem. Int. Ed. 2011, 50 (23), 5261-5263.

21. Marquez, C. A.; Fabbretti, F.; Metzger, J. O., Electrospray ionization mass spectrometric study on the direct organocatalytic alpha-halogenation of aldehydes. Angew. Chem. Int. Ed. 2007, 46 (36), 6915-6917.

22. Meyer, S.; Koch, R.; Metzger, J. O., Investigation of reactive intermediates of chemical reactions in solution by electrospray ionization mass spectrometry: Radical cation chain reactions. Angew. Chem. Int. Ed. 2003, 42 (38), 4700-4703.

23. Adlhart, C.; Chen, P., Fishing for catalysts: Mechanism-based probes for active species in solution. Helv. Chim. Acta 2000, 83 (9), 2192-2196.

24. Hinderling, C.; Adlhart, C.; Chen, P., Olefin metathesis of a ruthenium carbene complex by electrospray ionization in the gas phase. Angew. Chem. Int. Ed. 1998, 37 (19), 2685-2689.

25. van Leeuwen, P. W. N. M.; Kamer, P. C. J., Featuring Xantphos. Catal Sci Technol 2018, 8 (1), 26-113.

26. Hanson, B. E., New directions in water soluble homogeneous catalysis. Coord. Chem. Rev. 1999, 185-6, 795-807.

27. Goedheijt, M. S.; Reek, J. N. H.; Kamer, P. C. J.; van Leeuwen, P. W. N. M., A highly selective water-soluble dicationic palladium catalyst for the biphasic hydroxycarbonylation of alkenes. Chem. Commun. 1998, (22), 2431-2432.

28. Goedheijt, M. S.; Kamer, P. C. J.; van Leeuwen, P. W. N. M., A water-soluble diphosphine ligand with a large 'natural' bite angle for two-phase hydroformylation of alkenes. J. Mol. Catal. A: Chem. 1998, 134 (1-3), 243-249.

29. Chisholm, D. M.; Mclndoe, J. S., Charged ligands for catalyst immobilisation and analysis. Dalton T 2008, (30), 3933-3945.

30. Takahashi, R.; Kubota, K.; Ito, H., Air- and moisture-stable Xantphos-ligated palladium dialkyl complex as a precatalyst for cross-coupling reactions. Chem. Commun. 2020, 56 (3), 407-410.

31. Viciano-Chumillas, M.; Carbonell-Vilar, J. M.; Armentano, D.; Cano, J., Influence of Xantphos Derivative Ligands on the Coordination in Their Copper(I) and Silver(I) Complexes. Eur. J. Inorg. Chem. 2019, (25), 2982-2989.

32. Adams, G. M.; Colebatch, A. L.; Skornia, J. T.; McKay, A. I.; Johnson, H. C.; Lloyd-Jones, G. C.; Macgregor, S. A.; Beattie, N. A.; Weller, A. S., Dehydropolymerization of H3B.NIMeH2 To Form Polyaminoboranes Using [Rh(Xantphos-alkyl)] Catalysts. J. Am. Chem. Soc. 2018, $140(4), 1481-1495$.

33. Liu, M. L.; Ye, M. Y.; Xue, Y. Y.; Yin, G. D.; Wang, D. J.; Huang, J. K., Sonogashira coupling catalyzed by the $\mathrm{Cu}($ Xantphos)I-Pd(OAc)(2) system. Tetrahedron Lett. 2016, 57 (29), 31373139.

34. Huang, J. K.; Chan, J.; Chen, Y.; Borths, C. J.; Baucom, K. D.; Larsen, R. D.; Faul, M. M., A Highly Efficient Palladium/Copper Cocatalytic System for Direct Arylation of Heteroarenes: An Unexpected Effect of $\mathrm{Cu}$ (Xantphos)I. J. Am. Chem. Soc. 2010, 132 (11), 3674-3675.

35. Marchetti, M.; Botteghi, C.; Paganelli, S.; Taddei, M., Solid-liquid biphasic hydroformylation of olefins catalyzed by rhodium carbonyl complexes. Adv. Synth. Catal. 2003, 345 (11), 1229-1236.

36. Seomoon, D.; Lee, P. H., Xantphos as an efficient ligand for palladium-catalyzed crosscoupling reactions of aryl bromides and triflates with allyl acetates and indium. J. Org. Chem. 2008, 73 (3), 1165-1168.

37. Yin, J. J.; Buchwald, S. L., Pd-catalyzed intermolecular amidation of aryl halides: The discovery that xantphos can be trans-chelating in a palladium complex. J. Am. Chem. Soc. 2002, 124 (21), 6043-6048.

38. Artamkina, G. A.; Sergeev, A. G.; Beletskaya, I. P., Palladium-catalyzed reaction of aryl halides with ureas. Tetrahedron Lett. 2001, 42 (26), 4381-4384. 
39. Yunker, L. P. E.; Ahmadi, Z.; Logan, J. R.; Wu, W. Z.; Li, T. F.; Martindale, A.; Oliver, A. G.; Mclndoe, J. S., Real-Time Mass Spectrometric Investigations into the Mechanism of the Suzuki-Miyaura Reaction. Organometallics 2018, 37 (22), 4297-4308.

40. Janusson, E.; Zijlstra, H. S.; Nguyen, P. P. T.; MacGillivray, L.; Martelino, J.; Mclndoe, J. S., Real-time analysis of $\mathrm{Pd}-2(\mathrm{dba})(3)$ activation by phosphine ligands. Chem. Commun. 2017, 53 (5), 854-856.

41. Scheme drawn using www.catacycle.com: McFarlane, J.; Henderson, B.; Donnecke, S.; Mclndoe, J. S., An Information-Rich Graphical Representation of Catalytic Cycles. Organometallics 2019, 38 (21), 4051-4053.

42. Mclndoe, J. S.; Vikse, K. L., Assigning the ESI mass spectra of organometallic and coordination compounds. J. Mass Spectrom. 2019, 54 (5), 466-479.

43. Vikse, K. L.; Ahmadi, Z.; Luo, J. W.; van der Wal, N.; Daze, K.; Taylor, N.; Mclndoe, J. S., Pressurized sample infusion: An easily calibrated, low volume pumping system for ESI-MS analysis of reactions. Int. J. Mass Spectrom. 2012, 323, 8-13.

44. Yunker, L. P. E.; Stoddard, R. L.; Mclndoe, J. S., Practical approaches to the ESI-MS analysis of catalytic reactions. J. Mass Spectrom. 2014, 49 (1), 1-8.

45. Ray, A.; Bristow, T.; Whitmore, C.; Mosely, J., On-line reaction monitoring by mass spectrometry, modern approaches for the analysis of chemical reactions. Mass Spectrom. Rev. 2018, 37 (4), 565-579. 